Article

\title{
Assessment of the Resilience in SEPLS (Socio-Ecological Production Landscapes and Seascapes) in Yanuo Village, Xishuangbanna, Southwest China
}

\author{
Yunhui Yang ${ }^{1}$, Keyu Bai ${ }^{2,3}$, Guanhua Li ${ }^{1}$, Devra I. Jarvis ${ }^{4,5}$ and Chunlin Long ${ }^{1, *} \mathbb{B}$ \\ 1 College of Life and Environmental Sciences, Minzu University of China, Beijing 100081, China; \\ yangyunhui2008@126.com (Y.Y.); 18301231@muc.edu.cn (G.L.) \\ 2 Institute of Agricultural Resources and Regional Planning, Chinese Academy of Agricultural Sciences, \\ Beijing 100081, China; k.bai@cgiar.org \\ 3 China Office-Alliance of Bioversity International and CIAT, c/o CAAS, Room 611, \\ Old Building, No. 12 Zhongguancun Nandajie South Street, Beijing 100081, China \\ 4 Platform for Agrobiodiversity Research, c/o Alliance of Bioversity International and CIAT, \\ Maccarese, 00054 Rome, Italy; d.jarvis@cgiar.org \\ 5 Crop and Soil Sciences Department, Washington State University, Pullman, WA 99164, USA \\ * Correspondence: long.chunlin@muc.edu.cn
}

Received: 22 January 2020; Accepted: 24 April 2020; Published: 6 May 2020

check for updates

\begin{abstract}
Participatory 'assessment workshops' were held in 2018 in Yanuo Village, Xishuangbanna, Southwest China. The 'Indicators of Resilience in Socio-Ecological Production Landscapes and Seascapes (SEPLS)' tool was used to provide the community with a framework for discussion and analysis of socio-ecological processes essential for resilience. Workshops were planned and implemented by local people together with researchers from outside the community. Discussion, including a scoring process, was undertaken using a subset of twenty indicators designed to capture the communities' perceptions of factors affecting the resilience of their landscapes. The indicators were also used to provide the local community with a framework to discuss both current conditions of resilience and potential areas for improvement. A key result was that the existing community management approach did not include loss of traditional knowledge as a factor that would impact on the livelihoods and well-being of the community. A mechanism to encourage young people to inherit and actively use traditional knowledge was agreed to be necessary and included in economic activities. In addition, the socio-economic infrastructure in the community needs further improvement. This community management assessment framework in Yanuo Village can be scaled out to other communities in tropical montane regions with similar socio-economic environments by supporting stakeholders (policymakers, NGOs and development agencies, etc.).
\end{abstract}

Keywords: SEPLS; resilience; ecosystem services; Xishuangbanna; decision framework

\section{Introduction}

Complex links exist between humans and ecosystems [1]. The majority of ecosystems worldwide, e.g., agriculture, grassland, forest and marine ecosystems, have been impacted by humans through production activities. Unique landscapes and seascapes throughout the world have been created and sustainably managed by local communities adapting and benefiting from their surrounding environment [2,3]. Over the past 100 years, rapid social and economic development has disrupted these human-ecosystem links, threatening the survival of these unique and productive landscapes [2]. 
In response to this challenge, the Satoyama Initiative, started jointly by MOEJ (the Ministry of the Environment of Japan) and UNU-IAS (the United Nations University Institute for the Advanced Study of Sustainability) was created to support harmonious development of societies and nature. The Satoyama Initiative is now supported by the International Partnership for the Satoyama Initiative (IPSI), established in 2010, which, as of September 2019, consists of 258 member organizations. IPSI's collaborative work has developed a set of tools to measure the resilience of Socio-Ecological Production Landscapes and Seascapes (SEPLS), linked to recommendations for concrete community actions [2,4]. As a relatively new term, SEPLS refers to mosaics of production landscapes, which have been shaped through the interaction of humans and nature over time, and which simultaneously maintain biodiversity and provide ecosystem services [5]. The SEPLS framework evaluates ecosystem services along with the resilience and harmony of societies with nature, resulting in recommended actions for optimizing the sustainable management of the landscape being evaluated [6-10].

Conservation and sustainable management of SEPLS (socio-ecological production landscapes and seascapes) have been promoted by the IPSI since the Tenth Meeting of the Conference of the Parties to the Convention on Biological Diversity (CBD COP-10) in Aichi-Nagoya, Japan in 2010 [2]. Sustainable resilience in SEPLS (the capacity of SEPLS to absorb or recover from both natural and factitious disturbances) is crucial for securing ecosystem services for the long term, both benefiting local communities and contributing to the harmonious development of societies and nature globally. SEPLS have been shown to contribute to enhancing trust and social capital in communities and resolving conflicts $[2,3]$.

Sustainability, as one of global targets, is best addressed through multi-level governance [11]. National- and global-scale indicators may pretermit indicators critical for local communities [12]. Assessments that lack local perspectives can lead to loss of control over place, knowledge, or resources [13]. Many types of knowledge, including perceptions of local communities, can contribute to understanding and managing systems sustainably $[14,15]$.

Indicators of SEPLS resilience, developed jointly by Bioversity International, UNU-IAS, IGES (the Institute for Global Environmental Strategies), and UNDP (the United Nations Development Program) under IPSI have already been used in a more than 40 countries to assess SEPLS resilience, to monitor and evaluate project interventions on resilience and biodiversity conservation, to identify areas for support by community based organizations and to recommend policy support [2,16-18]. Unlike higher-level national- and global-scale indicators, the Indicators of Resilience in SEPLS introduced in this study are used with local communities so as to contribute to developing and providing a framework to enable community discussion on current resilience conditions and suggest actions for productive landscape management $[2,3]$.

The SEPLS in Yanuo Village, Jinuo Township, Xishuangbanna, Yunnan Province, Southwest China, is a result of the harmonious relationship between the local people and the nature they live in. The SEPLS in this community is a mosaic of ancient tea plantation, forests, upland agriculture, rubber and cash crop plantations, fishponds and home gardens. The livelihoods of local residents depend on the SEPLS diverse mosaic of ecosystems to access food and for employment etc. Specifically, vegetables, fish and other products are obtained by collecting wild plants and fishing. Local people achieve well-being from the SEPLS in Yanuo Village through a variety of ecosystem services in terms of provisioning, regulating services, cultural services, and supporting services, such as tea and medicinal plants, quality air and pollination, recreation and traditional knowledge, soil formation and nutrient cycling. The abundant agricultural and natural biodiversity, multiple land use types and ethnic culture in Yanuo, as in much of southwestern China, are currently under pressure from rapid economic development activities, including urbanization and the extension of cash crops. Thus the Yanuo case is a valuable representative for arguing sustainability in both biodiversity conservation and livelihood improvement.

The aim of this study was to employ the SEPLS Indicators of Resilience with the local community of Yanuo Village, to jointly develop a strategy for biodiversity conservation and the sustainable 
management of landscapes in Yanuo Village based on the observations, perceptions and experience of the local community. The SEPLS assessment framework developed in Yanuo will potentially serve as a guide for other communities in tropical montane regions, where it may be beneficial to be in harmony with nature under the current global trend of rapid socio-economic change.

\section{Materials and Methods}

\subsection{Study Area}

The research was carried out in Yanuo Village, Jinuo community (a township) in Xishuangbanna (Figures 1 and 2). Xishuangbanna is an administrative area at the prefectural level in southern Yunnan Province, a mountainous region of southwestern China. The climate is tropical. It is a key area in biogeography and a hotspot for biodiversity, with more than 5000 species of higher plants and 758 vertebrate species [19]. Yanuo Village has 127 households and 427 residents, all ethnic Jinuo people. The Jinuo are one of the linguistic groups in Xishuangbanna, with a population of less than 23,150 in 2010 [20]. Historically, they were famous for swidden cultivation and slash-and-burn agriculture, while supplementary food and other materials were provided by hunting and gathering. In addition, they raise livestock and poultry. Vegetables, subsistence food, oil and fiber were mainly obtained from the swidden fields [19].

The SEPLS in Yanuo Village is characterized by rich wild and cultivated biodiversity, and a unique ethnic culture with ecotourism potential. Ancient tea plantation management is widely practiced in villages. Tea cultivation is a traditional land use system, as tea trees have been cultivated and managed in natural forests by the Jinuo people for hundreds of years [19]. Home gardens, rubber and cash crop plantations, and fishponds are also managed by local people. 


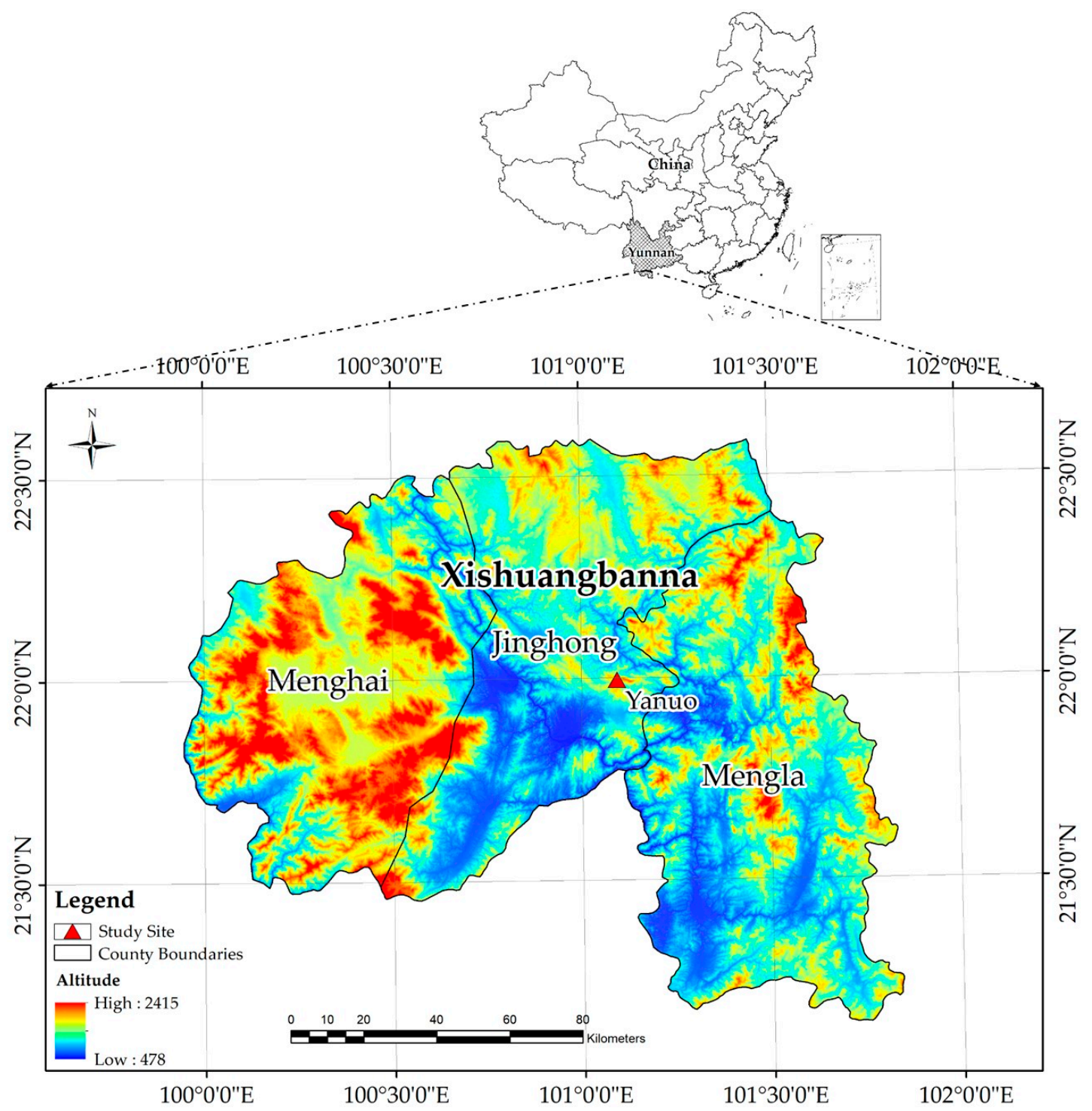

Figure 1. Location of Yanuo Village, Jinuo Community, Xishuangbanna, Southwest China (Source: http://www.gscloud.cn). 


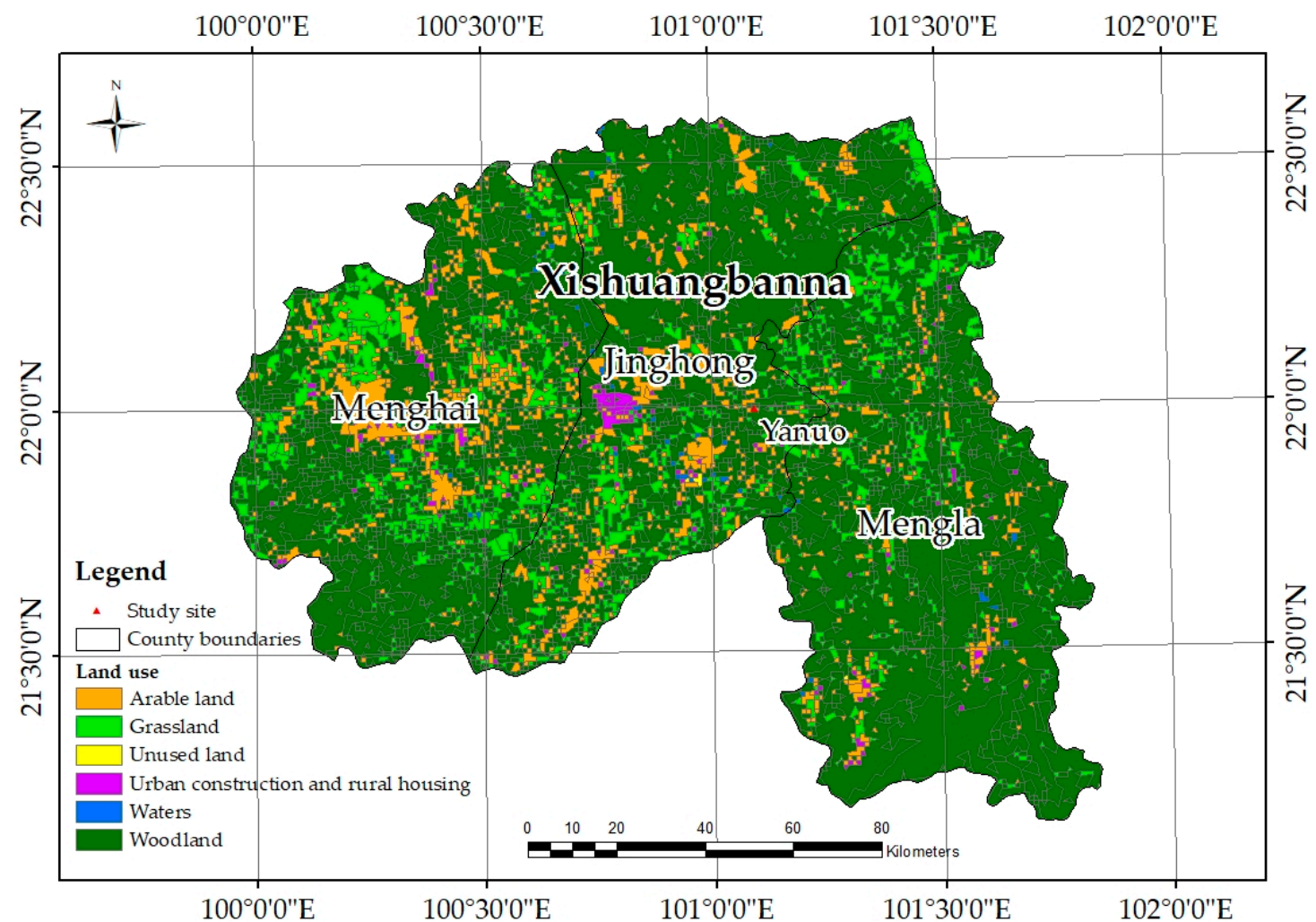

Figure 2. Land use of Xishuangbanna, Southwest China (Source: http://www.resdc.cn).

\subsection{Assessment of the Resilience in SEPLS}

We used a range of participatory research tools, mainly semi-structured interviews and group discussions, for data collection associated with the SEPLS in Yanuo Village, Xishuangbanna [21-24]. A framework was provided to the local community with both an analysis of current conditions of resilience and predictions of its dynamic change. The information was provided to the local community to be able to make quick and proactive efforts for conservation of the resilience of their SEPLS.

According to the "Toolkit for the Indicators of Resilience in SEPLS" [2], the progress of this assessment consisted of three stages: preparation, assessment workshop and follow-up [2] (Figure 3).

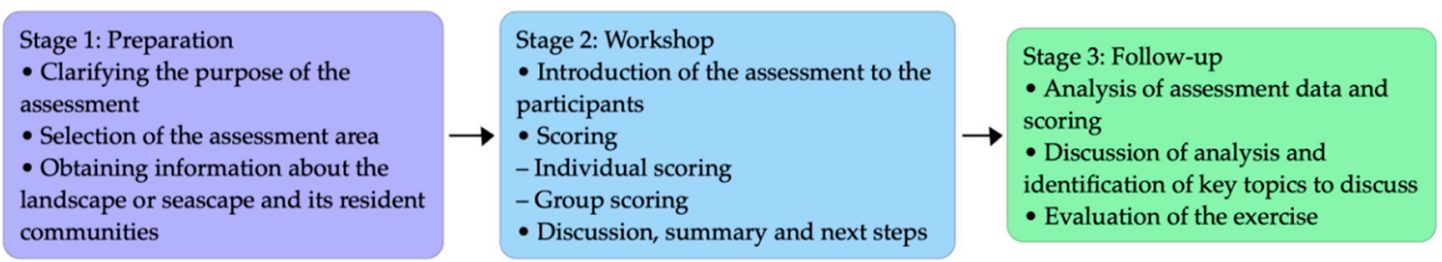

Figure 3. Flowchart of the process for assessment of SEPLS (Socio-Ecological Production Landscapes and Seascapes).

Figure 4 presents the conceptual model of linkages between ecosystem services and resilience in SEPLS, with the arrows in Figure 4 representing linkages between the SEPLS, ecosystem services and their assessment tools [25-27]. As spatial human-ecological systems, SEPLS provide humans with products and services needed for their wellbeing, while biodiversity is maintained or enhanced by the interaction between people and the landscape. Resilient SEPLS are defined as resilient systems that show sustainable community management, with appropriate management and utilization of natural resources and biodiversity [2]. Sustainable resilience in SEPLS is crucial for securing ecosystem services for the long term, because it has local level relevance and legitimacy matching the scales at which the stakeholders act and perceive their environment [28]. Biodiversity plays multiple roles in 
providing ecosystem services, including regulating ecosystem processes. In Yanuo, tea is one of the key species that provides both cash income and ecosystem services. The vertical distribution of vegetation in the ancient tea plantation (a tea-forest ecosystem) contributes to soil and water conservation in the mountainous landscape.

Twenty indicators of resilience in SEPLS were designed to capture community perceptions of different aspects of SEPLS that contribute to resilience (in five fields): landscape/seascape diversity and ecosystem protection; biodiversity (including agricultural biodiversity); knowledge and innovation; governance and social equity; and livelihoods and well-being [2,3] (Figure 5).

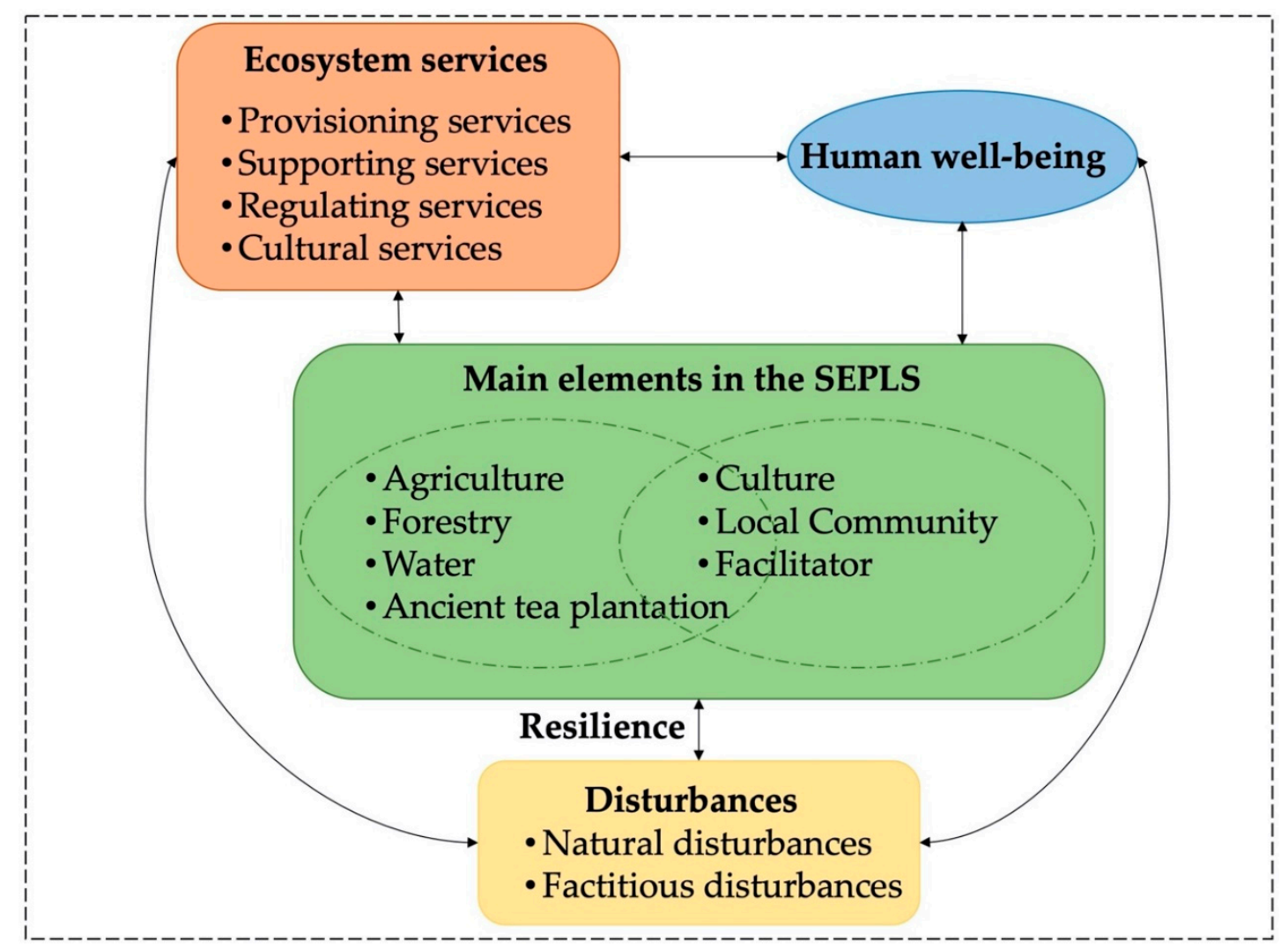

Figure 4. Conceptual model of linkages between ecosystem services and resilience in SEPLS research.

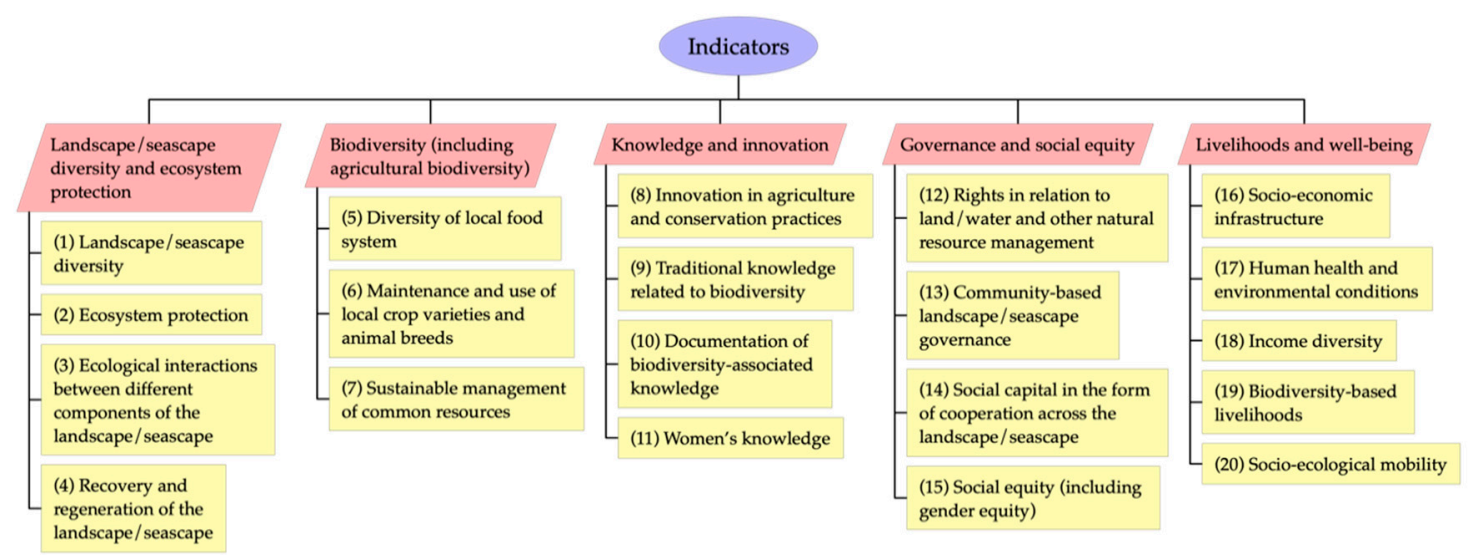

Figure 5. Indicators of resilience in SEPLS.

During the first stage (preparation), a preliminary workshop was organized for obtaining background information about Yanuo Village to determine the assessment area. The 20 selected indicators were translated from English into Chinese for the participants. Researchers ran the workshop 
as facilitators, whose roles involved planning, organizing, acting as rapporteurs, and following-up. Interpretation and explanation of the indicators were also essential for local people to clearly understand the meaning of the indicators.

In July 2018, after the preparation state, a two-day resilience assessment workshop took place in the house of an elderly participant in Yanuo Village. The actual duration each day was longer than planned as more time was needed to introduce clearly the assessment methodology to the participants. Gender and age balance was ensured in participant selection. Fifteen residents representing elders, indigenous youth returned from the city, tea farmers, women married into the village and the village chief participated in the workshop. Methods to assign a score and trend to each indicator were presented. Each participant was given a scorecard. Participants where shown how a score for each indicator represents the current situation and that the direction of the arrow represents an ongoing trend. The expected time frame for changes in trends is 10 years. The specific approach is to assign a score to all indicators based on the discussion of resilience in SEPLS, with a 5-point scale, to capture information about trends within the indicator categories. Scores for the resilience indicators were then collected. Average scores for each category were then discussed. Higher scores mean better landscape performance. For instance, five points means the landscape performs extremely well in the indicator being measured. By contrast, one point means very poor performance.

In August 2018, the researchers arranged a follow-up session (stage 3) to present the result and proposal for the framework for assessment (stage 2) to the Yanuo Community. The participants validated and endorsed their engagement in an assessment workshop (stage 2).

\section{Results}

In general, the score range of indicators in five fields was from 3 to 5 (Table 1, Figure 6), an indication that resilience levels in SEPLS in Yanuo Village were on average fairly high. The indicators such as 'heterogeneity and multifunctionality in the landscape', 'diversity of local food system' and 'use of local terminology or indigenous languages' all obtained 5 points, indicating that a variety of ecosystem services were functioning well. The mean score of 'biodiversity (including agricultural biodiversity)' was the highest (4 points) among the 5 categories. By contrast, 'livelihoods and well-being' had the lowest mean score (3.3 points). 
Table 1. Group scoring from Yanuo Village, Xishuangbanna.

\begin{tabular}{|c|c|c|}
\hline Indicators & Mean Score & Mean Trend \\
\hline Landscape/seascape diversity and ecosystem protection & 3.8 & \\
\hline 1. Heterogeneity and multifunctionality in the landscape & 5 & $\rightarrow$ \\
\hline 2. Areas protected for their cultural and ecological importance & 4 & $\uparrow$ \\
\hline 3. Sustainable use of resources & 3 & $\uparrow$ \\
\hline 4. Environmental security and safety & 3 & $\uparrow$ \\
\hline Biodiversity (including agricultural biodiversity) & 4.0 & \\
\hline 5. Agricultural biodiversity documented and conserved in community & 3 & $\rightarrow$ \\
\hline 6. Diversity of local food system & 5 & $\downarrow$ \\
\hline 7. Access and exchange of agricultural biodiversity & 4 & $\uparrow$ \\
\hline Knowledge and innovation & 3.9 & \\
\hline $\begin{array}{l}\text { 8. Innovation in agricultural biodiversity management for improved } \\
\text { resilience and sustainability }\end{array}$ & 4 & $\uparrow$ \\
\hline $\begin{array}{l}\text { 9. Transmission of traditional knowledge from elders, parents and peers to } \\
\text { the young people in a community }\end{array}$ & 3 & $\downarrow$ \\
\hline 10. Cultural traditions related to biodiversity & 4 & $\downarrow$ \\
\hline 11. Number of generations interacting with the land & 4 & $\downarrow$ \\
\hline 12. Practices of documentation and exchange of local knowledge scape & 3 & $\uparrow$ \\
\hline 13. Use of local terminology or indigenous languages & 5 & $\downarrow$ \\
\hline 14. Women's knowledge about biodiversity and its use & 4 & $\rightarrow$ \\
\hline Governance and social equity & 3.7 & \\
\hline 15. Local resource governance & 3 & $\uparrow$ \\
\hline 16. Autonomous access to indigenous land and natural resources & 4 & $\rightarrow$ \\
\hline 17. Gender & 4 & $\uparrow$ \\
\hline Livelihoods and well-being & 3.3 & \\
\hline 18. Socio-economic infrastructure & 3 & $\uparrow$ \\
\hline 19. Human health and environmental conditions & 4 & $\rightarrow$ \\
\hline 20. Income diversity & 3 & $\uparrow$ \\
\hline
\end{tabular}



\section{Mean score}

Figure 6. Radar diagram from a workshop in Yanuo Village.

\subsection{Landscape Diversity and Ecosystem Protection}

The landscape in Yanuo Village is composed of a diverse mosaic of ancient tea plantations, home gardens, rubber and cash crop plantations, fishponds, medicinal plants and other wild and cultivated crops. Among the four indicators in this field, 'heterogeneity and multifunctionality in the landscape' has remained constant in past 10 years. 'Areas protected for their cultural and ecological importance' 
was evaluated as 'high' with an upward trend. It means culture and ecology are important for the local community and a concern of local people. The indicators such as 'sustainable use of resources' and 'environmental security and safety' were evaluated as 'medium', but both categories had upward trends. A risk perception of sustainability was shared by participants.

\subsection{Biodiversity (Including Agricultural Biodiversity)}

'Diversity of local food system' was marked as 'very high' by the participants. Diversity of locally-sourced foods is very high and these foods are widely consumed. The other two indicators in this field, 'agricultural biodiversity documented and conserved in community' and 'access and exchange of agricultural biodiversity' were evaluated as 'medium' and 'high', respectively. The documentation and conservation of agricultural biodiversity were ignored to some degree by the community, while agricultural biodiversity access, exchange and use were ranked high. Consequently, the score of 'biodiversity (including agricultural biodiversity)' was highest (4 points) among the 5 categories.

\subsection{Knowledge and Innovation}

The largest number of indicators was in the 'knowledge and innovation' field. Communities frequently have an intimate knowledge of their physical environment and natural resources, particularly in indigenous communities such as Yanuo Village. Women's knowledge, experiences and skills were recognized and respected, judging from the high value of the score. Women's knowledge was specific on the production of particular crops and the process of traditional costumes. The mean score of the category 'knowledge and innovation' was 3.9, close to 'very high'. However, local knowledge and cultural traditions had downwards trends.

\subsection{Governance and Social Equity}

'Local resource governance' obtained 3 points. This reflected the traditional authorities and customary rules that are in place for effective utilization and conservation of local biodiversity, while the policy and legal environment still need to be improved. 'Autonomous access to indigenous land and natural resources' and 'gender' were evaluated as 'high'. Access to opportunities and resources was scored as fair and equitable for all community members, including women, at the household and community levels.

\subsection{Livelihoods And Well-Being}

The socio-economic infrastructure (for example, schools, hospitals, roads and transport; safe drinking water; markets; electricity and communication infrastructure) was scored as 'medium', i.e., can meet the basic needs of the community. There are schools and a hospital in the Jinuo Township. Some local people go to the township for the market fair every weekend. Although local people have access to community facilities by high-quality rural roads, transportation is still not convenient due to the terrain and tropical climate conditions in the mountains. The rainy season generally lasts for four months, and intermittent rain results in slippery roads. There are few public transportation options, available transportation means driving a car or riding a motorcycle. The health situation and the environmental conditions in Yanuo Village are good. Tea from ancient tea gardens has been the major source of cash income for hundreds of years.

\section{Discussion}

The assessment workshop conducted in Yanuo Village represented the current state of SEPLS perceived by the local people. The main fields that contribute to current resilience were identified, as was the urgent concerns for the community. The key topics of concerns and a threat to the SEPLS were socio-economic infrastructure, income diversity, local resource governance, landscape diversity, ecosystem protection, and the need for improvement in current land use management. In addition 
to the resilience status of the SEPLS, the stakeholder consultation process also reached a consensus on the following issues: inconvenient transportation and low diversity in economic activities, and urbanization leading to a decrease in the transmission of traditional knowledge are negatively affecting resilience in SEPLS in Yanuo Village.

\subsection{Factors Affecting the Resilience in SEPLS in Yanuo Village}

The indicator scores represented the local people's perceptions of urgency and need to deal with the factors negatively affecting the resilience in SEPLS in Yanuo Village. Biodiversity, including agricultural biodiversity, was the primary concern, followed by traditional knowledge. Furthermore, despite different scores being assigned to some indicators, similar trends were observed in the categories. For example, in the 'landscape/seascape diversity and ecosystem protection' category, the indicator 'sustainable use of resources' obtained less points ( 3 points) than the score of 'heterogeneity and multifunctionality in the landscape' (5 points); nevertheless the former indicator had an upward trend representing a positive state. Thus, this category can be considered to perform well.

The mean score of biodiversity, including agricultural biodiversity, was the highest, demonstrating that the resilience in SEPLS in Yanuo Village was providing ecosystem services related to biodiversity [29]. For example, the ancient tea plantations in Yanuo Village form a tea-forest ecosystem by planting tea seedlings under natural forest and by managing the system extensively $[19,30]$. The sustainability of this ecosystem is a result of biodiversity management (tea trees, shade trees, useful plants maintained in the garden by its owner, and other plants) [19]. Diversity of locally-sourced foods was also very high, these foods are widely consumed. A total of 179 species of edible plants consumed in Jinuo Community were reported in a previous study [31], and indication that Jinuo Community's biodiversity enhances ecosystem reliability ('reliability' refers to the probability that a system will provide a consistent level of performance over a given unit of time) by representing a form of biological insurance against the loss or poor performance of selected species [32].

Traditional knowledge and the ecosystems of SEPLS in Yanuo Village are a result of long-term coevolution. Combining traditional ecological knowledge with science is an effective strategy for sustainable utilization of resources [33]. The Jinuo practice a polytheistic religion, believing that all things have been endowed with a soul and spirit. Cutting big fig trees is commonly taboo. Local people have developed a swidden culture, considered to maintain a sustainable agro-ecosystem [34]. Education and employment opportunities in cities have led to a decrease in transmission of traditional knowledge from elders, parents and peers to the young people in the community. This has led to traditional knowledge being neglected in decision-making for landscape management, and may be contributing to the loss of biocultural diversity of the local communities [35].

'Livelihoods and well-being' was assigned the lowest mean score, mainly due to the mountainous traffic conditions. Although there are good local highway facilities, traffic is still not convenient in some situations (for example unfavorable weather conditions of the tropics), because of winding mountain roads. Sustainable and income-generating activities are few for the households. Reliance on ancient tea plantations as a single income-generating method is high. In case of a disaster affecting tea production, most families will have no other sources of income to support their livelihoods. Tourism in Yannuo Village, handicraft (traditional costumes), and tropical fruits are potential alternative sources of income. Diversifying economic activities would be a form of security for households in case of unexpected productive downturns or environmental disasters.

The assessment revealed abundant biodiversity and good ecosystem protection in SEPLS in Yanuo Village. Simultaneously, the disadvantage of the existing community management approach is ignorance of the potential shock of traditional knowledge loss, and the factors affecting livelihoods and well-being. A mechanism to encourage young people to inherit traditional knowledge actively needs to be established. Socio-economic infrastructure should also be further improved and economic activities that sustainably use traditional resources should be diversified and optimized. 


\subsection{Importance of the Assessment Workshop for Sustainability}

This study is an assessment using the SEPLS Indicators of Resilience in the mountainous regions in Yunnan, China. Integrating local perspectives and values into global scale indicator development efforts would help to develop research-based policy and action to confront the complex environmental challenges [36]. Firstly, the assessment is based on the perceptions and experiences of the local communities themselves. Selection of indicators from the full set is flexible, depending on the circumstances of each particular landscape or seascape and their associated communities. The Indicators of Resilience in SEPLS are easy to comprehend with the explanation by facilitators, and provide a framework for understanding resilience and its status and changes in SEPLS from a fresh perspective. Secondly, the method supported community empowerment in decision-making processes and adaptive management of their landscape. This management model promoted a greater sense of ownership among the local people, encouraging their active participation in policymaking for their community. Thirdly, the indicators provided a common language between various stakeholders, as well as better understanding the relationship between humans and nature [37].

\subsection{Proposal for an Assessment Framework}

Only one community was involved in the framework. More communities could be evaluated, and more system elements would be monitored, measured, or modeled in order to expand the long-term development of the region using the SEPLS Indicator framework [38]. A next step could be an exhaustive survey at the county or prefectural level to obtain quantitative indicators at a larger scale. Further improvement should be made to enhance communication with government and other institutions to link these indicators to broader national and international policy targets for sustainability.

\section{Conclusions}

In this study, 20 indicators for the assessment of resilience in SEPLS were used in Yanuo Village, Xishuangbanna, Southwest China. The results revealed that the biodiversity, including agricultural biodiversity, traditional knowledge and innovation were the primary concerns of the local people in Yanuo Village. It is worth noting that the main fields, including livelihoods and well-being, governance and social equity, and landscape/seascape diversity and ecosystem protection (e.g., socio-economic infrastructure, income diversity, local resource governance, sustainable use of resources, environmental security and safety) were shown to also be of urgent concern for the community.

Several common challenges of the assessment and relevant suggestions for conducting similar assessments are noted. First, insufficient time to explain the purpose of the exercise by facilitators results in confusion to the participants and limits their capacity to participate in discussions on indicators and results. Second, managing expectations from community members for the workshops is key to achieve the community's sense of ownership over their production and resource-management practices. Third, participation of all stakeholders is necessary to represent all social groups living in the community. In our study, women had more traditional knowledge than men in tropical montane regions.

Most important to the process is that the assessment considers the initiatives of local people as the basis for any discussion or assessment. These workshop results are also complemented by scientific data and information at the global and national levels as well as information from prior studies. SEPLS have protected biodiversity and provided ecosystem services for local communities around the world for thousands of years. The challenge is economic development, especially in montane regions, and the inappropriate management and utilization of natural resources, which has led to the degradation of natural resources and a reduction in ecosystem services [2]. As a tropical prefecture with multiple ethnic groups in southwest China, Xishuangbanna is famous for its rich biological and cultural diversity. It has been regarded as the global biodiversity hotspot [39]. Over 30 ethnic groups with abundant traditional knowledge have lived in the mountainous regions in southwest China for a long time. Use of indicators of resilience in SEPLS has enabled a collaborative identification of priority 
actions for adaptive management in the community. The indicators are of great significance to the local people and to the conservation of the biodiversity that the local people manage and that supports their livelihoods. The framework used should be expanded to other rich biocultural diversity areas in tropical montane regions with similar socio-economic environments.

Author Contributions: Conceptualization, C.L.; formal analysis, Y.Y.; investigation, Y.Y. and G.L.; writing-original draft preparation, Y.Y.; writing-review and editing, K.B., D.I.J. and C.L.; supervision, C.L.; project administration, C.L.; funding acquisition, C.L. All authors have read and agreed to the published version of the manuscript.

Funding: This research was funded by the National Nature Science Foundation of China (31761143001, 31870316), Biodiversity Survey and Assessment Project of the Ministry of Ecology and Environment of China (2019HJ2096001006), the Jiansheng Fresh Herb Medicine R \& D Foundation (JSYY-20190101-043), Minzu University of China (Collaborative Innovation Center for Ethnic Minority Development and yldxxk201819), the Ministry of Education of China and the State Administration of Foreign Experts Affairs of China (B08044).

Acknowledgments: We are very grateful to the Jinuo people who provided valuable information, traditional knowledge and culture, and hospitality as well. We would like to thank all people who contributed to the development of this study.

Conflicts of Interest: The authors declare no conflict of interest.

\section{References}

1. Fletcher, R.; Baulcomb, C.; Hall, C.; Hussain, S. Revealing marine cultural ecosystem services in the Black Sea. Mar. Policy 2014, 50, 151-161. [CrossRef]

2. UNU-IAS; Bioversity International; IGES; UNDP (Eds.) Toolkit for the Indicators of Resilience in Socio-Ecological Production Landscapes and Seascapes; UNU-IAS Policy Report38, 70; Bioversity International: Yokohama, Japan, 2014.

3. UNU-IAS; IGES (Eds.) Mainstreaming Concepts and Approaches of Socio-Ecological Production Landscapes and Seascapes into Policy and Decision-Making (Satoyama Initiative Thematic Review Vol. 2); United Nations University Institute for the Advanced Study of Sustainability: Tokyo, Japan, 2016.

4. Satoyama-Initiative. Available online: https://satoyama-initiative.org/about/ (accessed on 6 October 2019).

5. Gu, H.Y.; Subramanian, S.M. Drivers of change in socio-ecological production landscapes: Implications for better management. Ecol. Soc. 2014, 19, 41. [CrossRef]

6. Schaich, H.; Bieling, C.; Plieninger, T. Linking ecosystem services with cultural landscape research. GAIA 2010, 19, 269-277. [CrossRef]

7. Castonguay, A.C.; Burkhard, B.; Muller, F.; Horgan, F.G.; Settele, J. Resilience and adaptability of rice terrace social-ecological systems: A case study of a local community's perception in Banaue, Philippines. Ecol. Soc. 2016, 21, 15. [CrossRef]

8. Fisher, B.; Costanza, R.; Turner, R.K.; Morling, P. Defining and classifying ecosystem services for decision making. Ecol. Econ. 2009, 68, 643-653. [CrossRef]

9. Ouyang, Z.Y.; Wang, X.K.; Miao, H. A primary study on Chinese terrestrial ecosystem services and their ecological-economic values. Acta Ecol. Sin. 1999, 19, 607-613.

10. Gomez-Baggethun, E.; Ruiz-Perez, M. Economic valuation and the commodification of ecosystem services. Prog. Phys. Geog. Earth Environ. 2011, 35, 613-628. [CrossRef]

11. Berkes, F. Community-based conservation in a globalized world. Proc. Natl. Acad. Sci. USA 2007, 104, 15188-15193. [CrossRef]

12. Fraser, E.D.G.; Dougill, A.J.; Mabee, W.E.; Reed, M.; McAlpine, P. Bottom up and top down: Analysis of participatory processes for sustainability indicator identification as a pathway to community empowerment and sustainable environmental management. J. Environ. Manag. 2006, 78, 114-127. [CrossRef]

13. Sterling, E.J.; Betley, E.; Sigouin, A.; Gomez, A.; Toomey, A.; Cullman, G.; Malone, C.; Pekor, A.; Arengo, F.; Blair, M.; et al. Assessing the evidence for stakeholder engagement in biodiversity conservation. Biol. Conser. 2017, 209, 159-171. [CrossRef]

14. Chan, K.M.; Balvanera, P.; Benessaiah, K.; Chapman, M.; Diaz, S.; Gomez-Baggethun, E.; Gould, R.; Hannahs, N.; Jax, K.; Klain, S.; et al. Opinion: Why protect nature? Rethinking values and the environment. Proc. Natl. Acad. Sci. USA 2016, 113, 1462-1465. [CrossRef] [PubMed] 
15. Daniel, T.C.; Muhar, A.; Arnberger, A.; Aznar, O.; Boyd, J.W.; Chan, K.M.; Costanza, R.; Elmqvist, T.; Flint, C.G.; Gobster, P.H.; et al. Contributions of cultural services to the ecosystem services agenda. Proc. Natl. Acad. Sci. USA 2012, 109, 8812-8819. [CrossRef] [PubMed]

16. Holling, C.S. Resilience and stability of ecosystems. Annu. Rev. Ecol. S. 1973, 4, 1-23. [CrossRef]

17. Béné, C.; Newsham, A.; Davies, M. Making the Most of Resilience. IDS in Focus Policy Briefings, 2013. 32. Brighton: IDS. Available online: https://opendocs.ids.ac.uk/opendocs/handle/20.500.12413/2370 (accessed on 10 November 2019).

18. Takeuchi, K. Satoyama Initiative and Its Partnership: Lessons Learned for the Post-2020 Framework; Report at the Side Event at the CBD Regional Consultation Workshop on the Post-2020 Global Biodiversity Framework for Asia and the Pacific; The Satoyama Initiative: Nagoya, Japan, 2019.

19. Long, C.L.; Zhou, Y.L. Indigenous community forest management of Jinuo people's swidden agroecosystems in southwest China. Biodivers. Conser. 2001, 10, 753-767. [CrossRef]

20. The Population Census Office of the State Council, National Bureau of Statistics. Tabulation on the 2010 Population Census of the People's Republic of China. 2012. Available online: http://www.stats.gov.cn/tjsj/ pcsj/rkpc/6rp/indexch.htm (accessed on 6 October 2019).

21. Hill, R.; Dyer, G.A.; Lozada-Ellison, L.M.; Gimona, A.; Martin-Ortega, J.; Munoz-Rojas, J.; Gordon, I.J. A social-ecological systems analysis of impediments to delivery of the Aichi 2020 Targets and potentially more effective pathways to the conservation of biodiversity. Glob. Environ. Chang. Human Policy Dimens. 2015, 34, 22-34. [CrossRef]

22. Surya, S. Landscape ecological urbanism for restoration of Pallikaranai Marsh Land, Chennai, Tamil Nadu. Procedia Technol. 2016, 24, 1819-1826. [CrossRef]

23. Morrison, S.A. Designing virtuous socio-ecological cycles for biodiversity conservation. Biol. Conser. 2016, 195, 9-16. [CrossRef]

24. Murray-Rust, D.; Dendoncker, N.; Dawson, T.P.; Acosta-Michlik, L.; Karali, E.; Guillem, E.; Rounsevell, M. Conceptualising the analysis of socio-ecological systems through ecosystem services and agent-based modelling. J. Land Use Sci. 2011, 6, 83-99. [CrossRef]

25. Tengberg, A.; Fredholm, S.; Eliasson, I.; Knez, I.; Saltzman, K.; Wetterberg, O. Cultural ecosystem services provided by landscapes: Assessment of heritage values and identity. Ecosys. Serv. 2012, 2, 14-26. [CrossRef]

26. Uehara, T.; Niu, J.; Chen, X.; Ota, T.; Nakagami, K.I. A sustainability assessment framework for regional-scale Integrated Coastal Zone Management (ICZM) incorporating Inclusive Wealth, Satoumi, and ecosystem services science. Sustain. Sci. 2016, 11, 801-802. [CrossRef]

27. Landis, D.A. Designing agricultural landscapes for biodiversity-based ecosystem services. Basic Appl. Ecol. 2017, 18, 1-12. [CrossRef]

28. Fagerholm, N.; Käyhkö, N.; Ndumbaro, F.; Khamis, M. Community stakeholders' knowledge in landscape assessments-Mapping indicators for landscape services. Ecol. Indic. 2012, 18, 421-433. [CrossRef]

29. Mace, G.M.; Norris, K.; Fitter, A.H. Biodiversity and ecosystem services: A multilayered relationship. Trends Ecol. Evol. 2012, 27, 19-26. [CrossRef] [PubMed]

30. Saint-Pierre, C. Evolution of agroforestry in the Xishuangbanna region of tropical China. Agroforest. Sys. 1991, 13, 159-176. [CrossRef]

31. Wang, J.R.; Long, C.L. Ethnobotanical study of traditional edible plants of Jinuo nationality. Acta Bot. Yunnan. 1995, 17, 161-168.

32. Naeem, S.; Li, S. Biodiversity enhances ecosystem reliability. Nature 1997, 390, 507-509. [CrossRef]

33. Folke, C. Traditional knowledge in social-ecological systems. Ecol. Soc. 2004, 9, 7. [CrossRef]

34. Long, C.L. Plant diversity in swidden agroecosystems: A case study in Jinuo community of Xishuangbanna. In Regional Study on Biodiversity: Concepts, Frameworks, and Methods; Pei, S.J., Sajise, P.E., Eds.; Yunnan University Press: Kunming, China, 1995; pp. 53-77.

35. Wu, T.; Petriello, M.A. Culture and biodiversity losses linked. Science 2011, 331, 30-31. [CrossRef]

36. Sterling, E.J.; Filardi, C.; Toomey, A.; Sigouin, A.; Betley, E.; Gazit, N.; Newell, J.; Albert, S.; Alvira, D.; Bergamini, N.; et al. Biocultural approaches to well-being and sustainability indicators across scales. Nat. Ecol. Evol. 2017, 1, 1798-1806. [CrossRef]

37. UNU-IAS; Bioversity International; Ministry of the Environment, Government of Japan. Policy Report, Indicators of Resilience in Socio-Ecological Production Landscapes (SEPLS); UNU-IAS: Yokohama, Japan, 2013. 
38. Lee, K.-C.; Karimova, P.G.; Yan, S.-Y.; Li, Y.-S. Resilience assessment workshops: A biocultural approach to conservation management of a rural landscape in Taiwan. Sustainability 2020, 12, 408. [CrossRef]

39. Myers, N.; Mittermeier, R.A.; Mittermeier, C.G.; da Fonseca, G.A.B.; Kent, J. Biodiversity hotspots for conservation priorities. Nature 2000, 403, 853-858. [CrossRef] [PubMed] 